\title{
Editorial
}

\section{Espaços do gênero e poder}

\author{
Claudia Mora ${ }^{1}$ e Daniela Cáceres ${ }^{2}$ \\ Coordenadoras Dossiê: Gênero, poder e desigualdades
}

Revista Temas Sociológicos, N²2, 2018.

Este número especial da Revista Temas Sociológicos aborda as relações de poder constitutivas do gênero nos processos de organização e distribuição de recursos sociais no mercado do trabalho; nas significações que condicionam a incorporação dos seus assuntos e demandas na agenda pública, e em regimes sócio-políticos que contribuem è violência de gênero, uma das manifestações mais cruas da hierarquia e desigualdade neste âmbito. Neste dossiê, intitulado "Gênero, Poder e Desigualdades", o conjunto de trabalhos selecionados faz parte do núcleo reflexivo das ciências sociais sobre gênero e feminismos, e propõe a discussão em torno dos efeitos subjetivos e sociais da diferenciação genérica; os contextos sócio-políticos em que se desenvolvem relações de gênero/poder, assim como suas múltiplas manifestações cotidianas.

Este fascículo, convocado meses antes do chamado "maio feminista" chileno, vem a iluminar a prolífica reflexão em rela-

Doutora em Sociologia pela Northeastern University, Estados Unidos. Pesquisadora e professora da Universidade Academia de Humanismo Cristiano, Chile. Contato: claudiamoradelvalle@gmail.com

2 Candidata a Doutora em Sociologia pela Universidade Alberto Hurtado, Chile. Contato: dcaceres@uahurtado.cl 
ção com os processos de produção da diferença de gênero que, invisíveis pela sua cotidianidade, socavam os esforços democratizadores que os movimentos sociais têm impulsado no Chile -e na região- nas últimas décadas (Mora, 2013). A pressão dos movimentos recentes no país revelou a arbitrariedade e violência do gênero, gerando prometedores compromissos institucionais. No entanto, o impulso reacionário (backlash) que usualmente acompanha os desafios a grupos que monopolizam recursos e as estruturas de poder (Mansbridge e Shames, 2008), fundamenta-se, frequentemente, na legitimidade de uma ordem natural de gênero, que vive as práticas cotidianas dos sujeitos.

Os sistemas social, econômico e político desenvolvidos em relação com os interesses de grupos com poder não requerem da anuência ou, ainda, da consciência do privilégio de alguns; nem da força sobre outros para conseguir que atuem em contra dos seus próprios interesses. Porém, a perda de poder ativa resistências, expressadas em violência e descrédito, e, mais omnipresente, em guerra cultural: reclamações sobre o excessivo das mudanças, a sua desmedida rapidez e, fundamentalmente, em relação com a necessidade de preservar valores sociais que definem e identificam a nação (ibíd). Esta batalha se forja nas práticas cotidianas de diferenciação de gênero, nas que as lutas por justiça social se enquadram, frequentemente, em desafios marcadamente valóricos.

Os espaços de reprodução da diferença, assim como os processos que reiteram as desvantagens grupais das mulheres, são abordados neste número especial de Revista Temas Sociológicos focando-se em três dimensões centrais: mercado laboral, violência de gênero e transgressão normativa ao significante mulher. Os primeiros três artigos proporcionam uma análise sobre os regimes de gênero que regulam a incorporação e mobilidade laboral das mulheres no Chile. O mercado do trabalho chileno é uma das instituições que reflete mais claramente as desigualdades sociais, devido a que dispõe recursos -ingresso, autoridade, prestígio, por exemplo- em virtude de critérios formais, como o capital 
cultural acumulado, mas, principalmente, em virtude de critérios informais, como a associação em grupos sociais específicos. O gênero, a classe social e a origem nacional, entre outros, condicionam a posição dos trabalhadores na estrutura ocupacional, e, no caso das mulheres, a sua posição nestas estruturas reflete padrões de exclusão, desde que as concentra em certas atividades e hierarquias ocupacionais (Valenzuela e Mora, 2009).

As contribuições a este número dão conta de casos de estudo específicos em duas áreas de atividade -mineração e serviços-, abordando em primeiro lugar as limitações das políticas públicas e institucionais para a incorporação das mulheres no trabalho; logo, as implicações que a igualdade de gênero tem nos percursos laborais de mulheres profissionais e universitárias, e, terceiro, a significação das lideranças femininas na visão das próprias mulheres. Deste modo, esta seção do dossiê contribui à discussão de alguns aspectos fundamentais para a compreensão dos mecanismos de exclusão do trabalho: as limitações das políticas de inclusão perante a significação do gênero de trabalhadoras/es e empregadores/as que as desafiam; a reiteração da vinculação entre o reprodutivo com as expectativas e avaliação da liderança feminina, e a ingerência das conceptualizações subjetivas na identidade de "trabalhadora" das mulheres chilenas.

O primeiro artigo, intitulado "Equidade de gênero na grande mineração do cobre do Chile. Experiências de inserção laboral feminina em espaços masculinizados", de Gómez e Angelcos, propõe que, apesar da implementação de políticas públicas e institucionais de fomento à integração de mulheres no setor, persistem, como barreiras fundamentais à incorporação das mulheres na mineração, fronteiras sociais que delimitam a segregação das mulheres a trabalhos estereotipados por gênero. Os autores analisam como os estereótipos laborais associados ao masculino e feminino, e a vinculação entre mulher e mãe, definem as atividades e labores de homens e mulheres ao interior da atividade mineira, privilegiando distinções referidas aos corpos e a capacidades intelectuais "inatas". 
A partir de vinte entrevistas em profundidade a trabalhadoras nas divisões El Teniente e Chuquicamata, Gómez e Angelcos mostram que estereótipos associados ao trabalho feminino e masculino constituem fronteiras simbólicas que permitem a integração e legitimação da mulher na atividade mineira em espaços compatíveis com a definição simbólica de "o feminino", por exemplo, nas labores de gestão e administração na empresa mineira. Mas que os mesmos estereótipos reforçam a segregação das mulheres no caso do trabalho em terreno. Propõem os autores que "o traslado de lógicas familiares ao interior do trabalho -baseadas em uma relação paternalista entre trabalhadores do sexo masculino com trajetória e mulheres jovens recentemente ingressadas- facilita a relação entre diferentes gêneros, ao mesmo tempo que reproduz a posição de subordinação que têm as mulheres". Esta relação de subordinação é reiterada por homens e mulheres na insistência do papel maternal primário das mulheres. A atribuição exclusiva do cuidado e labores reprodutivos às mulheres trabalhadoras contribui a "uma pretensão de imutabilidade dos papéis dispostos na família, pelo que a maternidade constitui uma fronteira simbólica que limita as trajetórias de inserção feminina e desenvolvimento no setor mineiro". Concluem os autores que, "apesar dos avanços declarados pelas trabalhadoras da Divisão Chuquicamata e das demoras expressadas na Divisão El Teniente, as políticas institucionais das empresas mineiras ainda se apresentam como formas de solucionar problemáticas "das mulheres" ou "das mães", excluindo à população masculina na responsabilidade da criança e a família, reforçando com aquilo o imaginário de gênero".

Uma contribuição importante à discussão relativa à incorporação das mulheres ao mercado laboral chileno é desenvolvida pela antropóloga Carmen Gloria Godoy, quem assinala a relevância dos significados atribuídos à igualdade de gênero na configuração genérica de mulheres profissionais e universitárias jovens. A partir de 25 entrevistas a mulheres de estratos médios e altos, Godoy analisa a centralidade de uma noção de igualdade de gê- 
nero na construção dos seus projetos de vida e nas suas práticas cotidianas, no âmbito familiar, educativo e laboral.

O horizonte normativo que inspira as práticas cotidianas das mulheres no mercado do trabalho demonstra ser um fator determinante nas trajetórias laborais delas, na medida em que configura um "tipo ideal" em relação ao qual as performances individuais são avaliadas. Propõe a autora que, mesmo quando "a situação das mulheres, em geral, tinha melhorado em relação com a experiência das suas mães e avós. No entanto, essa igualdade manifestava-se de diferente modo se se tratava da família, o trabalho ou os estudos, assim também de acordo com as suas próprias histórias familiares". A "herança familiar" em relação à importância da igualdade de gênero incide de maneira determinante "na possibilidade de gerar um projeto de vida próprio (seja orientado ao desenvolvimento profissional, a maternidade ou outros projetos pessoais), no que a independência econômica adquire centralidade, aparece como uma das principais transformações relativas à concreção da igualdade de gênero, assim como a possibilidade e o desejo de ser bem sucedida profissionalmente".

A autora destaca a interseção da classe social na percepção do lugar ocupado nos círculos familiares, educacionais e laborais das mulheres no Chile, fazendo ver que a sensação de inadequação que acompanha às mulheres pode não ser experimentada por quem conta com mais recursos econômicos. Propõe Godoy que "a possibilidade de aceder a estudos superiores, impulsadas pelos seus próprios pais e tendo como modelo a uma mãe trabalhadora, para desenvolver uma carreira profissional, configura um horizonte no qual o trabalho se torna constitutivo da subjetividade -sem deixar de fora absolutamente à maternidade- resistindo-se assim às definições externas a respeito do que significa ser uma mulher e os seus limites de atuação".

Finalmente, o trabalho de Villarroel e Sánchez aprofunda na conceptualização da liderança feminina exercida no trabalho. Destacando a baixa participação laboral feminina no concerto global, 
as autoras dão luzes sobre as presunções que acompanham às mulheres que participam do mercado laboral, exercendo papéis de autoridade. Em concordância com a literatura, Villarroel e Sánchez mostram que o valor atribuído à liderança das mulheres continua baseando-se em capacidades estereotipicamente femininas. Propõem as autoras que as entrevistas permitem "observar um reconhecimento e valoração positiva do que socialmente seria eminentemente feminino, atribuindo à liderança características próprias do "ser mulher". Isto contribuiria com uma visão diferente da masculina, indicando que a sua presença permitiria transformar a forma de direcionar pessoas a seu cargo e o desenvolvimento das organizações nas que participam, um olhar que principalmente emerge desde o exercício das chefias femininas".

As autoras destacam que, no exercício da autoridade, a faixa etária das mulheres determina um estilo de liderança mais autoritário entre aquelas de mais idade, versus um estilo mais ideológico entre as mais jovens. No entanto, a participação das mulheres no trabalho e em papéis de liderança continua estando condicionada por presunções sobre as suas habilidades "naturais" pela mediação, o diálogo, e trabalho em equipe, no que a literatura tem denominado "formas maternalistas de liderança".

As contribuições deste dossiê ao conhecimento sobre as dinâmicas do mercado laboral que permeiam -e limitam- a participação das mulheres no trabalho produtivo, aprofundam uma análise que dá conta da persistência da definição do feminino como ligado ao reprodutivo e como inerentemente diferente do aporte masculino: as "habilidades brandas" das mulheres equilibrariam a competitividade e autoritarismo próprio dos homens. A insistência na definição genérica dos trabalhadores é um dos fatores-chave que previne a configuração do mercado laboral chileno como uma via concreta e íntegra de mobilidade social, e como um mecanismo de distribuição equitativo de recursos sociais.

Os efeitos materiais e simbólicos do cruzamento de múltiplas desigualdades sociais são analisados transversalmente desde a 
aproximação interseccional (Crenshaw, 1989, 1991) nos espaços criados pelo gênero, território e classe social. Com efeito, o gênero e a construção de um sistema social sexo/gênero (Rubin, 1996), binário e heteronormado, condiciona as experiências de vida assim como os imaginários coletivos de homens e mulheres (Nash, 2014). Quando o gênero se conjuga com outras variáveis, tais como a classe social ou a identidade sexual -que subverte a binariedade antes mencionada- funda novas condições de vulnerabilidade que podem implicar segregação, exclusão social e múltiplos tipos de violência.

A respeito da(s) violência(s) -um dos eixos que articulam este número-, embora a institucionalidade tem oferecido definições sobre violência de gênero, e particularmente contra a mulher, como um fenômeno transversal a mulheres e meninas, é preciso distinguir diferentes manifestações e gradientes de exposição à violência em virtude da interseção de desigualdades sociais, por exemplo, mulheres, pobres, imigrantes, de cor, lésbicas, pessoas com deficiência ou outros. Dito de outro modo, a violência contra as mulheres se relaciona com outras formas de violência relativas a condições sociais, como a pobreza, a marginalização, a exploração econômica, ou outras (Castañeda, Ravelo e Pérez, 2013, p. 13).

As particularidades geográficas, no âmbito das relações de gênero, oferecem uma leitura a respeito das condições de existência das mulheres em diferentes lugares do globo. Por isso, é especialmente significativa a inclusão, no eixo da violência de gênero, de duas pesquisas realizadas no México, um dos países com as taxas mais altas de violência contra a mulher e feminicídios/femicídios da América Latina. Ambos os artigos têm em comum uma visão crítica perante a Lei Geral de Acesso das Mulheres a uma Vida Livre de Violência (LGAMVLV), promulgada no México em 2007, apresentando cifras de mulheres vítimas de múltiplas violências -apesar dos vazios estatísticos a este respeito- e mapeando as resistências institucionais para executar mecanismos de prevenção. Ambas as autoras manifestam que o machismo, como dimensão estrutural, dificulta a eficácia de dita lei. 
Em consideração à complexidade da violência de gênero, $\mathrm{o}$ trabalho de Graciela Vélez e Héctor Serrano contribui à reflexão sobre o fenômeno desde a multiplicidade de fatores que incidem na violência, além de analisar o trabalho de prevenção e erradicação por parte do Estado e a política pública. O artigo, a partir de um diagnóstico contextual e de entrevistas a homens processados judicialmente por maus-tratos e/ou violência de gênero, distingue elementos que permitem visualizar pontos críticos que impedem avançar em termos de prevenção, tais como a falta de perspectiva de gênero institucional e a resistência a incorporá-la. Desta maneira, sobre a base do "modelo ecológico" desenvolvido por Bronfenbrenneren, os autores propõem uma análise integral da violência de gênero e, consequentemente, um desenho de políticas públicas que aborde a prevenção pensando em instrumentos com perspectiva de gênero que também estejam orientados a gerar condições de igualdade entre homens e mulheres.

Por outro lado, o artigo apresentado por Rocío Rosas propõe uma análise sobre a violência feminicida no Estado de Guanajuato e as suas implicações na vida das mulheres. Para isso, a metodologia empregada é a análise de fontes documentais, através da sistematização de feminicídios com presença em jornais locais, e a análise de dados secundários relativos à violência de gênero. Em virtude da convergência da análise apresentada, o trabalho propõe diferentes argumentos para explicar os feminicídios, realizando uma revisão conceitual e taxonômica sobre tipos de violência contra a mulher, complementado com definições de feminicídios a nível institucional/legal e acadêmico. Identifica, também, as características socioculturais do México, país cuja estrutura patriarcal perpetua os papéis tradicionais de gênero, a subordinação das mulheres e, com aquilo, a violência dirigida à mulher. Este trabalho tem especial relevância prática pela falta de dados sistematizados no lugar, apesar do incremento de delitos contra mulheres no setor do "corredor industrial", localizado no Estado de Guanajuato. 
A discussão sobre a violência, como problema macro e micro que se visualiza no plano estrutural e da interação social, tem a sua gênese nas relações assimétricas de poder entre homens e mulheres, e no lugar de postergação e subordinação ao género feminino. Existe uma vasta literatura sobre a distinção público/privado enquanto espaços generizados e de diferente valor: homens/público e mulheres/privado, refletido em dicotomias como a política e os labores de reprodução, ou o trabalho remunerado e o trabalho doméstico (não remunerado). Neste contexto, a violência vem a sublinhar o seu cenário relacional -uma questão de relação de poder-. Na ordem patriarcal, a violência contra a mulher evidencia a tentativa pela restauração da ordem que se vê ameaçada (Cáceres, 2016), e as suas expressões simbólica, econômica e física, assim como a mais extrema, o femicídio, projetam sinais de alerta que as ciências sociais não podem ignorar.

Em outra dimensão de análise, o suporte heteronormativo na diferenciação do espaço social público/privado configura um regime institucional construído em torno da diferença, que condiciona as possibilidades de existência de "subjetividades transgressoras". Um terceiro eixo deste número aborda os desafios envolvidos na subversão à norma e como dita transgressão tem efeitos nos âmbitos da experiência, as motivações e as representações.

O artigo apresentado por Paola Contreras aborda as consequências pessoais, familiares e sociais que experimentam as mulheres ao viver parte das suas maternidades encarceradas. A autora enfatiza a vivência destas mulheres como uma dupla condenação: social e penal. Fundamentalmente, porque são mulheres cuja infração ultrapassa o âmbito penal ao contravir o binômio ontologizado de mulher-mãe e, consequentemente, ao constituir-se como "mães más", julgadas e sancionadas socialmente. $\mathrm{O}$ artigo insiste nas lógicas do sistema penitenciário que reproduzem os papéis de gênero e complexificam a experiência da maternidade. Desta maneira, a historiadora propõe, desde a análise do discurso crítico feminista, uma reflexão sobre uma série de entrevistas rea- 
lizadas a mulheres que estiveram privadas de liberdade em Barcelona, Espanha, enquanto viviam a maternidade, para logo, desde as descobertas, abrir um debate que "desmantele" os preconceitos e estereótipos que estas mulheres carregam.

No âmbito da participação política, no contexto das lutas pelo reconhecimento e os direitos sexuais e reprodutivos das dissidências sexuais, as sociólogas Catalina Otárola e Catalina Tapia apresentam-nos uma pesquisa baseada na análise das motivações e experiências, como dimensões mutuamente implicadas, que impulsam a mulheres lésbicas a participar em diferentes organizações do movimento LGBTI + no Chile. O artigo parte da ideia de que desde o gênero se desenvolvem relações de poder assimétricas que influem nas experiências dos sujeitos/as e, neste sentido, o objeto de estudo envolve-se em um duplo registro: o da experiência vital e o da participação política de mulheres lésbicas, ambos em um mundo liderado historicamente por homens. Desta maneira, através de uma abordagem qualitativa, o artigo oferece-nos a possibilidade de conhecer as motivações desde uma lógica que ultrapassa o racional para enfatizar na importância das emoções e os valores como vetores de participação política.

A análise realizada pelas autoras é um contributo para as pesquisas existentes sobre movimentos sociais subalternos que têm despertado um especial interesse no seio das epistemologias feministas, fundamentalmente pelos processos de subalternização desenvolvidos sob agendas políticas mais amplas, nas quais o gênero e as diversas dimensões implicadas nesta categoria analítica acabam em um espaço de opacidade no contexto da interseccionalidade política (Walby, Armstrong e Strid, 2012; Crenshaw, 1991).

Os três eixos temáticos do número especial que aqui apresentamos -mercado laboral, violência de género e transgressão normativa ao significante mulher- contribuem a evidenciar, a partir de casos de estudo empíricos, que a construção genérica é sempre relacional, socio-histórica e atravessada pelo poder. Como já 
susteve Joan Scott há mais de três décadas: o gênero é um dos principais campos de articulação de poder, e um facilitador da significação do poder através da sua construção mútua (1986).

Finalmente, este dossiê encerra com dois trabalhos relativos às duas seções complementares para conformar o corpus completo da Revista Temas Sociológicos. O artigo de Juan Pablo Venables, "Sociologia e opinião pública: desmontando um dispositivo", reflete sobre formas de poder que constroem realidades e agendas públicas. $\mathrm{O}$ artigo constitui uma contribuição significativa à compreensão da opinião pública na sua qualidade de artefato construído pelas sondagens de opinião, as quais legitimam uma certa política e consolidam as relações de força que a fazem possível. Venable releva a necessidade de considerar nas sondagens não só as crenças e opiniões dos indivíduos, senão que, também, os "constrangimentos, sanções ou restrições sobre eles, assim como o aspecto material expressado em ações ou práticas que dão a sua especificidade à realidade social". Assim, o autor dá luzes em relação à necessidade de explorar não só estatísticas e opiniões dos sujeitos, mas também de esclarecer os processos sociopolíticos, culturais e econômicos que condicionam as suas percepções, práticas e posições sociais.

Para concluir, a resenha escrita pelas sociólogas Javiera Osses e Daniela Valencia, em referência ao livro "Ser Política no Chile", da socióloga e cientista política Julieta Kirkwood, situa neste número especial uma das obras mais influentes para o feminismo no Chile. A pouco mais de trinta anos da sua publicação, a análise da relação entre mulheres e política, assim como a invisibilidade e subalternidade das mulheres em uma série de espaços sociais, parece uma leitura ainda vigente e, neste sentido, o aporte desta resenha ao dossiê, lembrando a uma das mulheres mais significativas no campo dos estudos de gênero e a mulher, é uma homenagem à sua contribuição.

Em consideração a que o gênero é uma dimensão de desigualdade social que se materializa em condições de existência, 
a aposta deste dossiê é relevar os estudos sociais de gênero que, sustentados desde um paradigma crítico, alcancem no Chile, no debate acadêmico e político, o lugar que tanto a multiplicidade de centros de estudo e pesquisa quanto o sistema internacional de direitos humanos têm lhes conferido. Cada vez mais, os movimentos de mulheres e LGBT+ colorem as ruas do mundo, fazendo visíveis demandas históricas habitualmente desatendidas. Os movimentos feministas do Chile 2018 advertem sobre as experiências de desigualdade de mulheres e minorias sexuais, desafiando as resistências institucionais à incorporação da perspectiva de gênero, os discretos protocolos contra o assédio sexual nas instituições universitárias, e as minguadas leis em matéria de direitos humanos das mulheres e as minorias sexuais, demonstrando, com isso, a necessidade de colocar o foco nas relações entre o gênero, o poder e as desigualdades sociais.

\section{Referências}

Butler, J. (2004). Undoing gender. New York: Routledge.

Cáceres, D. (2016). Sobre la semántica del femicidio en Chile. Sociedad y economía, 239-262.

Castañeda, M., Ravelo, P. e Pérez, T. (2013). Feminicidio y violencia de género en México: omisiones del Estado y exigencia civil de justicia. Iztapalapa Revista de Ciencias Sociales y Humanidades, 74, 11-39.

Crenshaw, K. (1989). Demarginalizing the intersection of Race and Sex: A black Feminist Critique of Antidiscrimination Doctrinem Feminist Theory and Antiracist Politics. University of Chicago Legal Forum, 138-167.

Crenshaw, K. (1991). Mapping the Margins: intersectionality, identity Politics, and Violence against Women of Color. Stanford Law Review, 1241-1299.

Mansbridge, J. \& Shames, S. L. (2008). Toward a theory of backlash: Dynamic resistance and the central role of power. Politics $\mathcal{E}$ Gender, 4 (4), 623-634.

Mora, C. (2013). Desigualdad en Chile: la continua relevancia del género. Santiago de Chile: Ediciones Universidad Alberto Hurtado. 
Nash, M. (Ed). (2014). Feminidades y masculinidades. Madrid: Alianza Editorial.

Rubin, G. (1996). El tráfico de mujeres: notas sobre la "economía política" del sexo, en M. Lamas, El género: la construcción cultural de la diferencia sexual (pp. 35-96). México D.F.: PUEG, Miguel Ángel Porrúa.

Scott, J. (1996). El género como categoría de análisis histórico, en M. Lamas, El género: la construcción cultural de la diferencia sexual (pp. 265-302). México D.F.: PUEG, Miguel Ángel Porrúa.

Valenzuela, M. E. \& Mora, C. (2009). Trabajo doméstico: un largo camino hacia el trabajo decente. Santiago de Chile: Organización Internacional del Trabajo.

Walby, S., Armstrong, J. \& Strid, S. (2012). Instersectionality: Multiple inequalities in Social Theory. Sociology, 224-240. 